\title{
Sleep Disorders in Parkinsonian Macaques: Effects of L-Dopa Treatment and Pedunculopontine Nucleus Lesion
}

\author{
Hayat Belaid, ${ }^{1}$ Joëlle Adrien, ${ }^{1}$ Elodie Laffrat, ${ }^{1}$ Dominique Tandé, ${ }^{1}$ Carine Karachi, ${ }^{1}$ David Grabli, ${ }^{1}$ Isabelle Arnulf, ${ }^{2}$ \\ Stewart D. Clark, ${ }^{3}$ Xavier Drouot ${ }^{4}$ Etienne C. Hirsch, ${ }^{1}$ and Chantal François ${ }^{1}$ \\ ${ }^{1}$ Institut National de la Santé et de la Recherche Médicale Unité Mixte de Recherche-S975, Université Pierre et Marie Curie Paris 06, Unité Mixte de Recherche-S975, \\ CNRS Unité Mixte de Recherche 7225, and Centre de Recherche-Institut du Cerveau et de la Moelle, Groupe Hospitalier Pitié-Salpêtrière, 75013 Paris, France, \\ ${ }^{2}$ Service des pathologies du sommeil, Assistance Publique-Hôpitaux de Paris, Groupe Pitié-Salpêtrière, 75013 Paris, France, ${ }^{3}$ Department of Pharmacology and \\ Toxicology, University at Buffalo, Buffalo, New York 14214, and ${ }^{4}$ Physiology Department, CHU de Poitiers, 8600 Poitiers, France
}

Patients with Parkinson's disease (PD) display significant sleep disturbances and daytime sleepiness. Dopaminergic treatment dramatically improves PD motor symptoms, but its action on sleep remains controversial, suggesting a causal role of nondopaminergic lesions in these symptoms. Because the pedunculopontine nucleus (PPN) regulates sleep and arousal, and in view of the loss of its cholinergic neurons in PD, the PPN could be involved in these sleep disorders. The aims of this study were as follows: (1) to characterize sleep disorders in a monkey model of PD; (2) to investigate whether L-dopa treatment alleviates sleep disorders; and (3) to determine whether a cholinergic PPN lesion would add specific sleep alterations. To this end, long-term continuous electroencephalographic monitoring of vigilance states was performed in macaques, using an implanted miniaturized telemetry device. 1-Methyl-4-phenyl-1,2,3,6-tetrahydropyridine treatment induced sleep disorders that comprised sleep episodes during daytime and sleep fragmentation and a reduction of sleep efficiency at nighttime. It also induced a reduction in time spent in rapid eye movement (REM) sleep and slow-wave sleep and an increase in muscle tone during REM and non-REM sleep episodes and in the number of awakenings and movements. L-Dopa treatment resulted in a partial but significant improvement of almost all sleep parameters. PPN lesion induced a transient decrease in REM sleep and in slow-wave sleep followed by a slight improvement of sleep quality. Our data demonstrate the efficacy of L-dopa treatment in improving sleep disorders in parkinsonian monkeys, and that adding a cholinergic PPN lesion improves sleep quality after transient sleep impairment.

Key words: cholinergic neurons; L-dopa; macaques; Parkinson's disease; pedunculopontine nucleus; sleep disorders

\section{Introduction}

Patients with Parkinson's disease (PD) experience a range of symptoms, including significant sleep disturbances, with excessive daytime sleepiness and "sleep attacks," insomnia, reduced total sleep time and sleep efficiency, rapid eye movement (REM) sleep behavior disorder, and a marked increase in the number of nocturnal awakenings compared with healthy controls (Gagnon et al., 2002; Hobson et al., 2002; Rye, 2006; Wailke et al., 2011; Yong et al., 2011). Whether sleep disorders are generated by the disease itself, dopaminergic (DA) treatment, or non-DA lesions is incompletely known (Arnulf et al., 2002). The effects of DA drugs on sleep and alertness in PD patients are variable and sometimes opposite, depending on the level of nocturnal bradykinesia, the time of intake, and the nature of the drug (i.e., levodopa vs DA

Received Jan. 15, 2014; revised May 23, 2014; accepted May 29, 2014.

Author contributions: C.F. designed research; H.B., E.L., D.T., C.K., I.A., X.D., and C.F. performed research; S.D.C. and C.F. contributed unpublished reagents/analytic tools; H.B., J.A., and C.F. analyzed data; H.B., J.A., C.K., D.G., I.A., E.C.H., and C.F. wrote the paper.

This work was supported by "Laboratoires Servier" from the program "Investissements d'avenir" (ANR-10-IAIHU06) and National Institutes of Health Grant R00DA024754. We thank Nick Barton for language editing.

The authors declare no competing financial interests.

Correspondence should be addressed to Dr. Chantal François, Centre de Recherche-Institut du Cerveau et de la Moelle, Unité Mixte de Recherche-S975, Hôpital de la Salpêtrière, 47 bd de l'Hôpital, 75013, Paris, France. E-mail: chantal.francois@upmc.fr.

DOI:10.1523/JNEUROSCI.0181-14.2014

Copyright $\odot 2014$ the authors $\quad 0270-6474 / 14 / 349124-10 \$ 15.00 / 0$ agonist). DA agonists taken during daytime may cause severe sleepiness and sleep attacks (Arnulf, 2005, Hobson et al., 2002), with sleepiness increased by increasing dosage, whereas L-dopa has the opposite effect (Bliwise et al., 2012). In parkinsonian macaques, selective D1 receptor agonist was recently reported to improve REM sleep and excessive daytime sleepiness, whereas D2 receptor agonist revealed no effect (Hyacinthe et al., 2014).

Degenerative changes in PD also affect non-DA structures involved in the regulation of arousal and REM sleep, such as the noradrenergic locus ceruleus system and the cholinergic pedunculopontine nucleus (PPN) system, known to degenerate in advanced PD (Hirsch et al., 1987; Jellinger, 1988). Recently, changes in sleep quality were reported in patients with $\mathrm{PD}$ with severe gait disorders, who had been implanted with electrodes for deep brain stimulation applied to the PPN (Arnulf et al., 2010; Peppe et al., 2012), thus raising the question of a role of PPN neuronal loss in the sleep abnormalities associated with PD. However, data in the literature on animal models are not conclusive, and no study has evaluated the effect of a specific cholinergic PPN lesion on sleep disorders observed in parkinsonian models. The development of animal models, such as the monkey rendered parkinsonian with 1-methyl-4-phenyl-1,2,3,6-tetrahydropyridine (MPTP), is a key element to understanding the pathophysiology of sleep disorders in patients with PD. The relevance of MPTP-treated macaques for exploring the sleep deficits that occur in PD has already been 
Table 1. Summary of the effect of MPTP intoxication and of subsequent L-dopa treatment on sleep parameters ${ }^{a}$

\begin{tabular}{|c|c|c|c|c|c|c|c|c|c|}
\hline \multirow[b]{2}{*}{ Treatment } & \multirow[b]{2}{*}{ TST min } & \multirow{2}{*}{$\begin{array}{l}\text { Sleep } \\
\text { efficiency }\end{array}$} & \multicolumn{3}{|l|}{$\begin{array}{l}\text { Night } \\
\text { TST (100\%) }\end{array}$} & \multirow{2}{*}{$\begin{array}{l}\text { WASO } \\
(\%)\end{array}$} & \multirow{2}{*}{$\begin{array}{l}\text { Wake } \\
(\%)\end{array}$} & \multirow{2}{*}{$\begin{array}{l}\text { Sleep onset } \\
\text { to REM (min) }\end{array}$} & \multirow{2}{*}{$\begin{array}{l}\text { Daytime } \\
\text { sleep (\%) }\end{array}$} \\
\hline & & & Stage 1-2 & SWS & REM & & & & \\
\hline Control mean & 595.8 & 83.0 & 54.5 & 23.8 & 22.0 & 14.2 & 17.0 & 49.6 & 1.6 \\
\hline SEM & 7.0 & 2.0 & 4.0 & 3.0 & 1.0 & 2.0 & 1.5 & 10.0 & 1.0 \\
\hline MPTP mean & $410.5^{* * *}$ & $57.1^{* * *}$ & $67.4^{* *}$ & $12.5^{* * *}$ & $17.3^{* * *}$ & $40.0^{* * *}$ & $42.9^{* * *}$ & $101.5^{*}$ & $12.8^{* * *}$ \\
\hline SEM & 25.0 & 3.6 & 3.2 & 2.8 & 1.7 & 4.9 & 3.8 & 10.1 & 2.7 \\
\hline L-Dopa mean & $452.9^{*}$ & $63.1^{*}$ & 64.9 & 13.2 & $19.1^{*}$ & 32.4 & $37.0^{*}$ & 98.8 & $5.8^{* *}$ \\
\hline SEM & 18.1 & 2.6 & 4.1 & 3.4 & 1.3 & 3.7 & 2.6 & 10.8 & 1.6 \\
\hline PPN 3w mean & 489.4 & 69.3 & 66.2 & 14.2 & 18.2 & 35.8 & 30.7 & 127.0 & 4.7 \\
\hline SEM & 36 & 6.5 & 4.4 & 2.2 & 3.5 & 14.9 & 6.5 & 15.1 & 1.6 \\
\hline
\end{tabular}

${ }^{a}$ Mean values of sleep parameters were calculated in 4 macaques in the control state, after MPTP intoxication, and then after L-dopa treatment, in 3 macaques 3 weeks ( $3 \mathrm{w}$ ) after a unilateral PPN lesion and in one of these macaques after a second PPN lesion in the other hemisphere. MPTP values were compared with control values, and L-dopa values with MPTP values. Level of significance was given only in the case of statistical significance for each individual.

${ }^{*} p<0.05 ;{ }^{* *} p<0.01 ;{ }^{* * *} p<0.001$ : Kruskal-Wallis test followed by Mann-Whitney $U$ test in the event of statistically significant differences.

demonstrated (Barraud et al., 2009). Moreover, we reported that the combination of DA and PPN lesions in monkeys enabled us to reproduce a close model of advanced PD (Grabli et al., 2013). Using this approach, our aim was to investigate whether sleep deficits in PD reflect the disease itself or the side effects of DA medications, or other degenerative features, such as cell loss in non-DA structures. For this purpose, we implanted a miniaturized telemetry device to perform long-term continuous electroencephalographic monitoring of vigilance states in unrestrained macaques at baseline (control state), after MPTP intoxication, with L-dopa treatment, and then after cholinergic PPN lesion.

\section{Materials and Methods}

Animals. The study was performed on 4 adult male macaque monkeys (Macaca fascicularis) and was performed in strict accordance with the European Union Directive of 2010 (Council Directive 2010/63/EU) for the care and use of laboratory animals. The authorization for conducting our experiments was approved by the Committee on the Ethics of Animal Experiments (agreement Ce5/2012/049). The animals were kept under standard conditions $\left(12 \mathrm{~h}\right.$ light/dark cycle [light off at $20: 00 \mathrm{~h}$ ], $23^{\circ} \mathrm{C}$, and $50 \%$ humidity). Monkeys weighed $4-6 \mathrm{~kg}$ and were $3-5$ years of age.

Apparatus. Macaques were chronically implanted with a radio-telemeter transmitter for continuous and long-term recording. The transmitter implant consisted of a sterile, disk-shaped, three-channel biopotential device (D70-EEE, Data Sciences International) for measuring electroencephalography (EEG), electro-oculography (EOG), and electromyography (EMG) signals. Extending from the transmitter body were flexible leads consisting of one ground lead and 3 channels. Biopotential signals were transmitted to two receivers mounted on the primate cage and then forwarded to a data exchange matrix serving as a multiplexer and connected through a ribbon cable to a computer for data recording and storage.

Transmitter implantation. After premedication with $0.05 \mathrm{ml} / \mathrm{kg}$ Robinul and $10 \mathrm{mg} / \mathrm{kg}$ ketamine given intramuscularly, animals were intubated and anesthetized with isoflurane (1\%-2\%). Analgesia was provided on the day of surgery by a single intramuscular injection of 2 $\mathrm{mg} / \mathrm{kg}$ Tolfedine (tolfenamic acid, $4 \%$ ). The transmitter was implanted within the abdominal muscle layers. The electrode biopotential leads were tunneled subcutaneously to the skull. Two EEG electrodes were screwed unilaterally into the skull $10 \mathrm{~mm}$ lateral to the midline: one above the frontal cortex and the other $30 \mathrm{~mm}$ more posterior (EEG channel). Two electrodes for EOG were affixed at the level of the orbital arch bone unilaterally: one at the top and the other on the external side (EOG channel). The two EMG leads were sutured to the neck musculature. After surgery, animals were returned to their home cage and allowed to recover for 3 weeks. Buprenorphine (Buprecare, $0.02 \mathrm{mg} / \mathrm{kg}$ i.m.) and prophylactic antibiotic cover (Clamoxyl, $20 \mathrm{mg} / \mathrm{kg}$ ) were provided for 2 weeks postoperatively.

MPTP intoxication. All MPTP injections $(0.2-0.4 \mathrm{mg} / \mathrm{kg}$, in $\mathrm{NaCl}$ $0.9 \%)$ were intramuscular and were performed under light anesthesia (ketamine $0.4-0.5 \mathrm{mg} / \mathrm{kg}$ ). A progressive administration protocol was used, with injections performed at an interval of 3-7 d until the emergence of all parkinsonian symptoms. Intoxication was stopped once all the motor parkinsonian symptoms had appeared.

Dopaminergic therapy. For levodopa (L-dopa) testing, doses of levodopa with benserazide at a ratio of 4:1 (Modopar Dispersible, Roche) were given orally. The dosage required to alleviate motor abnormalities in the MPTP-treated monkeys was $20 \mathrm{mg} / \mathrm{kg}$, as already reported in the literature (Bezard et al., 1997), and was given twice per day (at 10:00 h and at 14:00 h), with an effect that lasted for between $3 \mathrm{~h} 30 \mathrm{~min}$ and $4 \mathrm{~h}$ after administration. As L-dopa has a long bioavailability at the beginning of the disease, no medication was given after 18:00 h. Our aim was to obtain a long duration benefit of L-dopa after some days of treatment, as that reported in PD patients, who gradually improve on L-dopa therapy. Such an improvement generally requires $9 \mathrm{~d}$ to achieve a maximum response (Barbato et al., 1997). Specifically, each animal received L-dopa treatment twice daily for $8-12 \mathrm{~d}$, and the sleep recording was only performed afterward.

Motor score. The severity of parkinsonism before, during, and after MPTP intoxication and after L-dopa treatment was evaluated in the home cage using a rating scale. This scale includes 7 items (spontaneous activity, bradykinesia, tremor, freezing, posture, balance deficit, and feeding) (Herrero et al., 1993b), rated between 0 (normal) and 3 (maximal disability), with a total score out of 21 . Evaluations were performed by the same observer every $2 \mathrm{~d}$ after the first injection of MPTP and until the day the animal was killed. Spontaneous activity was also quantified using an automated activity digitalizing system (VigiePrimates, Viewpoint).

PPN lesion. We performed PPN lesions stereotaxically on three MPTPtreated monkeys according to the procedure previously described (Karachi et al., 2010). We used injections of a fusion of diphtheria toxin and the peptide urotensin II $(10 \mu \mathrm{l}, 20 \%)$. This fusion toxin was developed to specifically kill cholinergic neurons of the PPN (Clark et al., 2007), which have previously been shown in rodents to express the urotensin II receptor (Clark et al., 2001). Lesions were performed unilaterally in a total of three macaques, and in one of these macaques a second PPN lesion was added in the other hemisphere.

Sleep data. For each of the four animals, sleep recordings were performed in the home cage during a $24 \mathrm{~h}$ period, always starting at 10:00 h. During this $24 \mathrm{~h}$ period, the light was on from 8:00 $\mathrm{h}$ to 20:00 $\mathrm{h}$. Two $24 \mathrm{~h}$ recording sessions per week were performed over several weeks in each experimental condition: 5 recordings at baseline (i.e., control state, 3 weeks after surgery), one recording at day 1 after the first MPTP injection, 5 recordings after MPTP treatment (2 months after the last MPTP injection), and 4 or 5 recordings during L-dopa therapy (sleep recordings starting $8-12 \mathrm{~d}$ after the beginning of L-dopa therapy). Two $24 \mathrm{~h}$ recording sessions were also performed in three MPTP-treated animals 1,2, and 3 weeks after each PPN lesion.

The polysomnographic signals were transmitted to a receiver and then to an acquisition device (Dataquest A.R.T., Data Sciences International). Software (Neuroscore, Data Sciences International) was used for sleep scoring to obtain hypnograms. Sleep-wake stage scoring was performed in $20 \mathrm{~s}$ epochs so that the whole epoch was assigned to one stage. The 
vigilance stages identified were "active wake," "wake" (with $\alpha$ waves), "light sleep" (Stage 1 and Stage 2 pooled together), "slow-wave sleep" (SWS) (Stage 3 and Stage 4 pooled together) and "rapid eye movement" (REM) sleep. Non-REM sleep (NREM) included sleep Stages 1-4. As unconventional sleep stages, also named dissociate sleep stages (e.g., NREM sleep with rapid eye movements, or REM sleep without atonia) may occur in parkinsonism, sleep recordings were reviewed by clinicians (I.A., X.D.) trained to score PD sleep in humans. Two categories of muscle tone during REM sleep time were distinguished for the 20 s REM epochs: complete atonia and increased muscle tone for $>50 \%$ of the epoch.

Artifacts, occasionally produced by excessive movements during wakefulness, were excluded from analyses. They represented no more than $2 \%$ of total recording time. The following parameters were calculated for each 12hour period of darkness: total sleep time (TST), duration of each stage, wake time after sleep onset (WASO), sleep efficiency, REM sleep latency (time from nighttime start to REM sleep onset), and daytime sleep. The number of sleep transitions between wake, NREM, and REM stages was also quantified. All macaques were videotaped during the $24 \mathrm{~h}$ sleep recordings, video and sleep data being recorded synchronously.

Immunohistochemistry. All macaques were deeply anesthetized and intracardially perfused with 4\% PFA in PBS. Brains were removed, immersed in $30 \%$ sucrose in PBS, and then frozen and cut into 50 - $\mu \mathrm{m}$-thick sections transversally. Series of regularly interspaced $(500 \mu \mathrm{m}$ apart) fresh-frozen sections of macaque brains were processed for tyrosine hydroxylase (TH) immunohistochemistry (François et al., 1999). Another series of regularly interspaced (500 $\mu \mathrm{m}$ apart) sections were processed for NADPH diaphorase histochemistry as previously described (Hirsch et al., 1987).

Data analysis. The extent of DA denervation was assessed by counting $\mathrm{TH}^{+}$neurons on 8 regularly interspaced nigral sections (every 500 $\mu \mathrm{m})$ covering the anteroposterior extent of the structure. The sections were matched anatomically in each of the brains while verifying that the cross-sections of the substantia nigra were similar in all individuals. Estimation of the total number of DA neurons was performed using a semiautomatic stereology system with a computer-based system (Mercator, ExploraNova). The number of $\mathrm{TH}^{+}$neurons in the locus coeruleus and the number of $\mathrm{NADPH}^{+}$, non-NADPH ${ }^{+}$, and Nissl-stained neurons in both the PPN and the adjacent cuneiform nucleus were also counted using the same method and were expressed as the number of cells per $\mathrm{mm}^{3}$. These data were compared with those obtained from 5 intact macaques (M. fascicularis) from previous studies (Karachi et al., 2010; Grabli et al., 2013) and whose brain sections were processed under the same conditions.

Statistical analysis. A Mann-Whitney rank-sum test was performed to determine the loss of $\mathrm{TH}^{+}$neurons between MPTP-treated animals and controls. A Kruskal-Wallis test, followed by a Mann-Whitney $U$ test in the event of statistically significant differences, was applied for the comparison of sleep parameters at baseline, after MPTP intoxication, and after L-dopa treatment for each animal. Level of significance was given only in case of statistical significance for each individual. Results with $p \leq$ 0.05 were considered significant for all the analyses. Data are presented as mean \pm SEM
CTL

Active wake

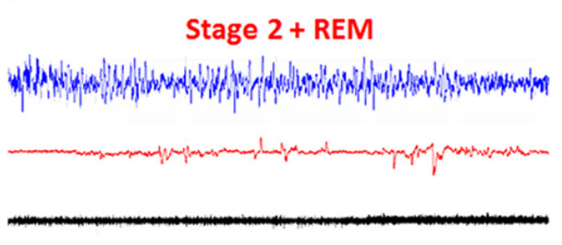

Stage 2

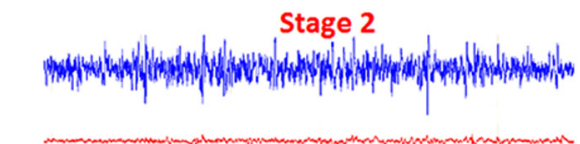

SWS
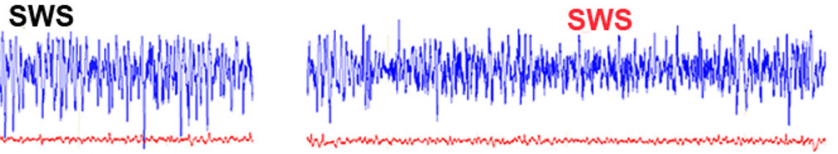

B

MPTP

tage 2 + REM

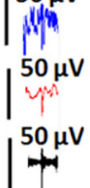

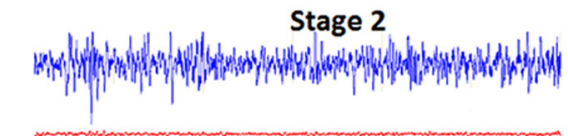
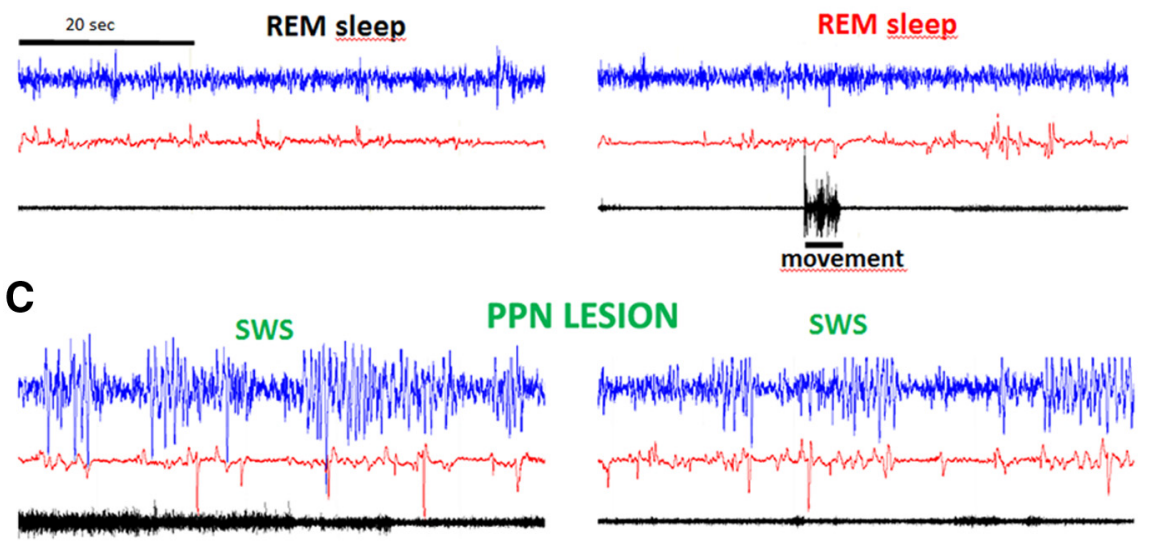

Figure 1. Examples of 1 min polysomnographic recordings. A, At baseline (control state, CTL). B, After MPTP intoxication. C, At 1 week after further PPN lesion. Blue represents EEG; red represents EOG; black represents EMG. Note the existence, after MPTP, of eye movements during Stage 2 (top right: Stage $2+$ REM), and of movements during Stage 2 and REM sleep, and the occurrence, after PPN lesion, of ample $\delta$ frequencies on EEG and increased muscle tone.

Table 2. Motor scores obtained after MPTP intoxication $(n=4)$, under L-dopa treatment $(n=4)$, and 3 weeks after PPN lesion $(n=3)^{a}$

\begin{tabular}{llll}
\hline Monkey ID & MPTP & L-Dopa & PPN lesion \\
\hline 1 & 10 & 2.5 & - \\
2L & 13 & 2.5 & NR \\
3R & 8,5 & 2 & 6,5 \\
3L & 8,5 & 2 & 6 \\
4L & 10 & 2 & 7,5
\end{tabular}

${ }^{a}$ The motor score of the most severely disabled macaque (2) was not recorded (NR) after PPN lesion in the left (L) hemisphere because of severe disequilibrium and falls. No PPN lesion was performed for animal 1. R, right.

\section{Results}

Basal sleep-wake states

Sleep parameters were recorded for 3-4 weeks to assess the baseline sleep/wakefulness patterns and features. Sleep measures are shown in Table 1 . During wakefulness, $\alpha$ waves $(8-12 \mathrm{~Hz})$, commonly occurring in relaxed wakefulness in humans, were rarely observed (Fig. 1A). Sleep spindles of $14-16 \mathrm{~Hz}$ and high-amplitude K-complexes were common in Stage 2 NREM sleep. Rapid eye movements were frequently present in the EOG. The EMG activ- 
A

Spontaneous activity
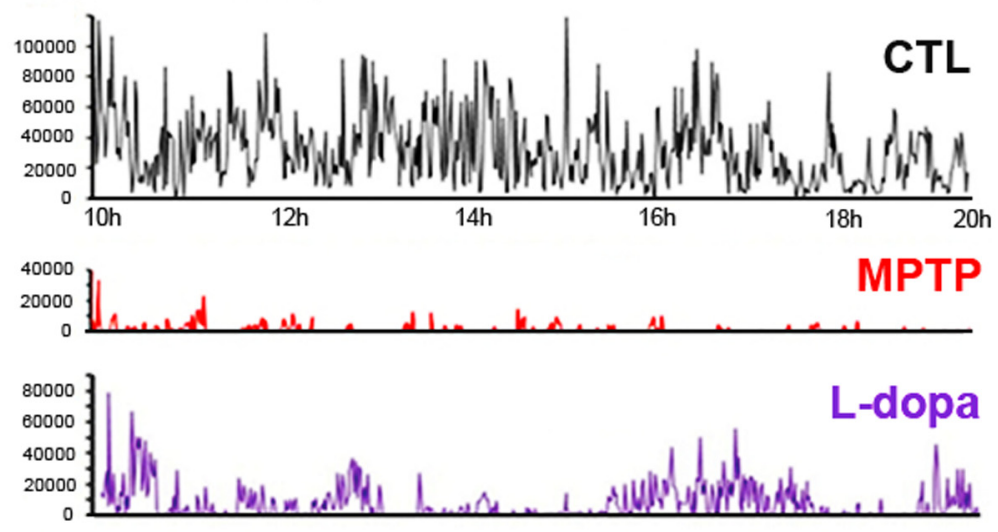

B

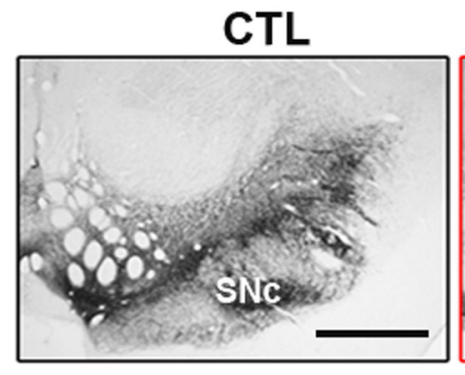

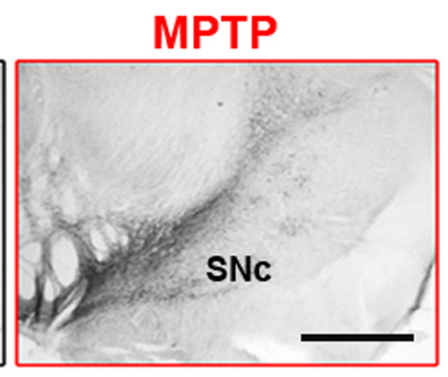

C Number of $\mathrm{TH}+$ neurons

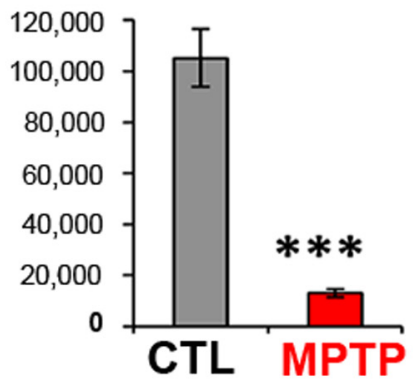

Figure 2. Measurement of motor disability and assessment of DA lesion within the mesencephalon of MPTP-treated macaques. $\boldsymbol{A}$, Examples of $10 \mathrm{~h}$ daytime recording of spontaneous activity of MPTP-treated Macaque 3 during the control (CTL) state, after MPTP intoxication, then after L-dopa medication. L-Dopa treatment (bottom graph) was given at $10 \mathrm{~h}$ and at $14 \mathrm{~h}$. $\boldsymbol{B}$, Example of TH immunostaining in the mesencephalon of a control macaque and an MPTP-treated macaque. Scale bar, $2 \mathrm{~mm}$. $\mathbf{C}$, Graphic representation of the number of TH ${ }^{+}$neurons in the substantia nigra pars compacta (SNc) in the 4 MPTP-treated macaques and 5 controls. ${ }^{* *} p<0.001$ (Mann-Whitney rank-sum test).

ity recorded from posterior neck muscles was at its lowest level during REM sleep.

The macaques slept for $42 \%$ of the $24 \mathrm{~h}$, mostly during the night. During the dark period, REM sleep occupied $21.9 \pm 1.0 \%$ of the TST and was more abundant at the end of the night. SWS represented $23.8 \pm 3.0 \%$ of the TST, was more frequently observed at the beginning of the night, and was more abundant in the 2 young animals ( 3.5 years) than in the older ones ( 5 years). A reduced amount of sleep, consisting exclusively of light sleep episodes (Stages 1 and 2), was observed during the daytime (1.6 \pm $1.0 \%$ of the $12 \mathrm{~h}$ ).

\section{Parkinsonian symptoms and DA cell loss}

After MPTP intoxication, monkeys progressively developed motor symptoms: hypokinesia (freezing, bradykinesia, and reduction of spontaneous activity), rigidity, tremor, and postural disturbances. After stabilization of symptoms (6 weeks after the last MPTP injection), all the monkeys developed severe parkinsonism and scored between 8 and 13 on a scale of 21 (Table 2). For example, the spontaneous activity of the animals was reduced by $\sim 85 \%$ (Fig. $2 A$ ). L-Dopa treatment partially reversed parkinsonism, with a decrease of the scores on the parkinsonian rating scale and an increase in spontaneous activity in all MPTP-treated monkeys (Fig. 2A).

Microscopic examination showed that the number of THimmunoreactive cell bodies was dramatically reduced in the substantia nigra pars compacta of MPTP-treated macaques (Fig. 2B) compared with 5 control animals. Quantitative assessment revealed a statistically significant loss of $85 \%(105,187 \pm 5193$ neu- rons vs 15,512 \pm 2995 neurons, $p<0.001$, Mann-Whitney $U$ test) (Fig. 2C). A statistically significant loss of $19 \%$ of $\mathrm{TH}^{+}$ neurons was also observed in the ventral tegmental area $(19,024 \pm 7572$ neurons vs 13,171 \pm 3290 neurons, $p=0.015$, Mann-Whitney $U$ test). Because the locus ceruleus has a role in sleep-wake control and its noradrenergic neurons degenerate in $\mathrm{PD}$, we quantified $\mathrm{TH}^{+}$neurons in the locus coeruleus of our animals. No statistically significant loss of $\mathrm{TH}^{+}$neurons occurred in the locus coeruleus $(7906 \pm 89$ neurons vs $7307 \pm 259$ neurons, $p=0.28$, Mann-Whitney $U$ test).

\section{Effects of MPTP intoxication and then of L-dopa treatment upon sleep architecture}

Major sleep impairments appeared during the night after the first MPTP injection (data not shown). The most striking changes observed consisted of a drastic reduction of REM sleep (3.9 $\pm 4.6 \%$ vs $21.9 \pm 1.0 \%, p<0.01$ ), with large variations between animals (loss ranging from $32 \%$ to $99 \%$ ), a decrease of $15 \%$ in TST and of $48 \%$ in SWS stage, and an increase in sleep fragmentation.

After stabilization of PD symptoms, thus 1-2 months after the last MPTP injection, sleep parameters were modified both quantitatively (Table 1) and qualitatively (Figs. 2, 3, and 4) compared with baseline. Episodes of sleepiness occurred in daytime (from $1.6 \pm 1.0 \%$ of light NREM sleep to $12.8 \pm 2.5 \%$ of the 12 daytime hours, $p<0.001$ ), appearing less frequently in the less disabled macaques. During the night, MPTP-treated monkeys exhibited decreased sleep efficiency (from $83.2 \pm 2.0 \%$ to $58.9 \pm 3.5 \%, p<$ 0.001 ), and increased sleep fragmentation, as assessed by the increase in the number of stage transitions and of awakenings (Fig. 


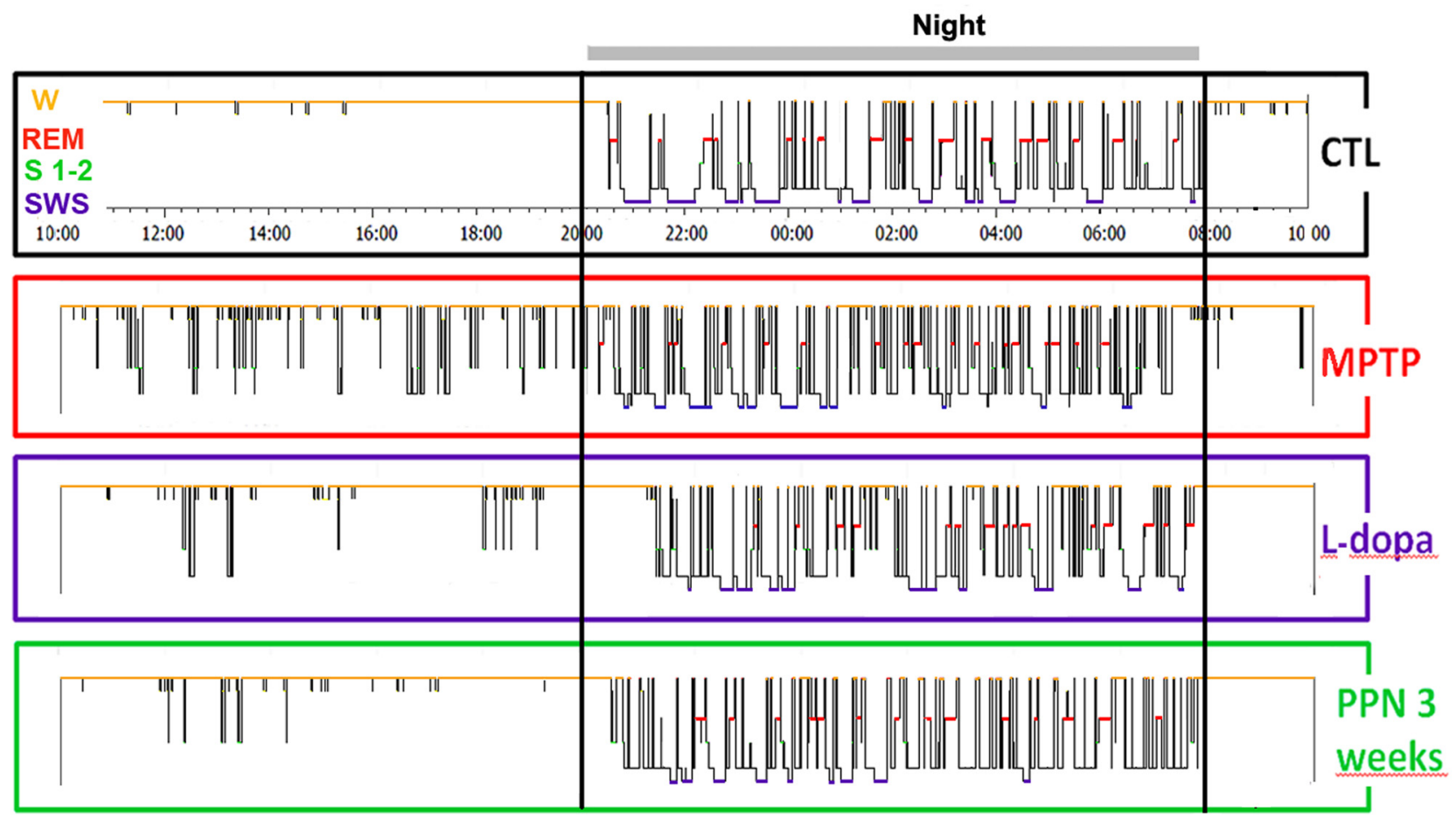

Figure 3. Examples of hypnograms of $24 \mathrm{~h}$ recordings in Macaque 3 at baseline (CTL), 1 month after MPTP intoxication, after 1 week of L-dopa treatment, and 3 weeks after subsequent PPN lesion. MPTP intoxication induced sleep episodes during the day and the impairment of sleep organization with marked sleep fragmentation and awakenings during the night. L-Dopa had a beneficial effect on daytime and nighttime sleep. A subsequent PPN lesion resulted in a better sleep quality 3 weeks after the lesion than after MPTP intoxication alone.

$4 C$ ). The time spent in SWS and in REM sleep was reduced (from $23.8 \pm 3.0 \%$ to $12.2 \pm 2.8 \%$ of the TST, $p<0.001$; and from $21.9 \pm 1.0 \%$ to $16.8 \pm 1.5 \%$ of the TST for REM sleep, $p<0.001$ ). REM sleep latency increased from $50 \pm 10 \mathrm{~min}$ to $105 \pm 10 \mathrm{~min}$ $(p<0.05)$ (Fig. 4A).

L-Dopa given at a therapeutic dose ( $20 \mathrm{mg} / \mathrm{kg}$ twice daily) and after habituation over 8-12 d of treatment alleviated the motor symptoms during 3-4 h after treatment and induced in parallel a significant sleep improvement (Fig. 3). Daytime sleepiness was reduced from $12.8 \pm 2.5 \%$ before L-dopa to $4.8 \pm 1.6 \%$ of the $12 \mathrm{~h}(p<0.01)$ (Table 1). L-Dopa treatment induced slight but significant effects in the number of stage transitions and awakenings, the relative time awake, WASO, TST, and REM sleep time $(p<0.05)$ (Fig. $4 A-C)$, the effects being more pronounced in the most severely disabled macaque. Improvement was also observed for NREM sleep, but the effect was not statistically significant.

Effects of MPTP intoxication and then of L-dopa treatment on muscle tone and movements during sleep

Muscle tone increased during nighttime and daytime sleep after MPTP intoxication (Figs. $2 B$ and 5). This increase developed progressively during the first month after the last MPTP injection and then decreased slightly after stabilization of symptoms but never disappeared. It was characterized by the occurrence of high-amplitude EMG bouts during REM and NREM sleep. REM with muscle tone during $>50 \%$ of an epoch occupied $17 \pm 2 \%$ of the REM sleep time (which was never observed during the control state). Abnormal epochs containing rapid eye movements during light NREM sleep (indicative of a dissociate stage between NREM and REM sleep) were observed during $7 \pm 2 \%$ of light NREM sleep. They most often occurred before the onset of REM sleep episodes (Figs. 2B, top, and 5).
MPTP also increased the number of movements and the number of awakenings during sleep. Loss of balance during sleep was observed, which sometimes led monkeys to sleep lying on the floor (which never happened in the control state), and even to fall from their nest. Although falls were observed in one animal on awakening from REM sleep, no abnormal movements or behaviors could be detected during REM sleep. Enhanced muscle tone during REM sleep and an increased number of movements were obvious 1 month after stabilization of parkinsonian symptoms and were slightly decreased but still visible up to 6 months after MPTP intoxication. Daytime L-dopa treatment tended to restore normal sleep-related hypotonia during both nighttime and daytime sleep (Fig. 5), but this finding was not statistically significant.

\section{Effects of PPN lesion on sleep architecture}

A PPN lesion was performed unilaterally in three MPTP-treated macaques. Quantitative assessment revealed a loss of $17 \%$ of $\mathrm{NADPH}^{+}$neurons in the first macaque, $27 \%$ in the second, and $26 \%$ in the third compared with 5 control animals (Fig. $6 A$ ). The loss of noncholinergic neurons in the PPN was 5\%, 15\%, and 7\%, respectively, and in the adjacent cuneiform nucleus was 5\%, 11\%, and $10 \%$, respectively. These lesions impaired gait and worsened postural parameters, beginning $2 \mathrm{~d}$ after the lesion and being maximal 4-7 d after the lesion. When axial motor symptoms were maximal, muscle tone of limbs was markedly decreased on the side contralateral to the lesion but increased on the side ipsilateral, as previously described (Grabli et al., 2013).

Sleep was evaluated without L-dopa medication. We observed an increase in sleep fragmentation compared with the MPTP state (data not shown) and in nighttime wake, and a decrease in sleep efficiency, SWS, and REM sleep (Fig. 6B). Moreover, PPN 
A
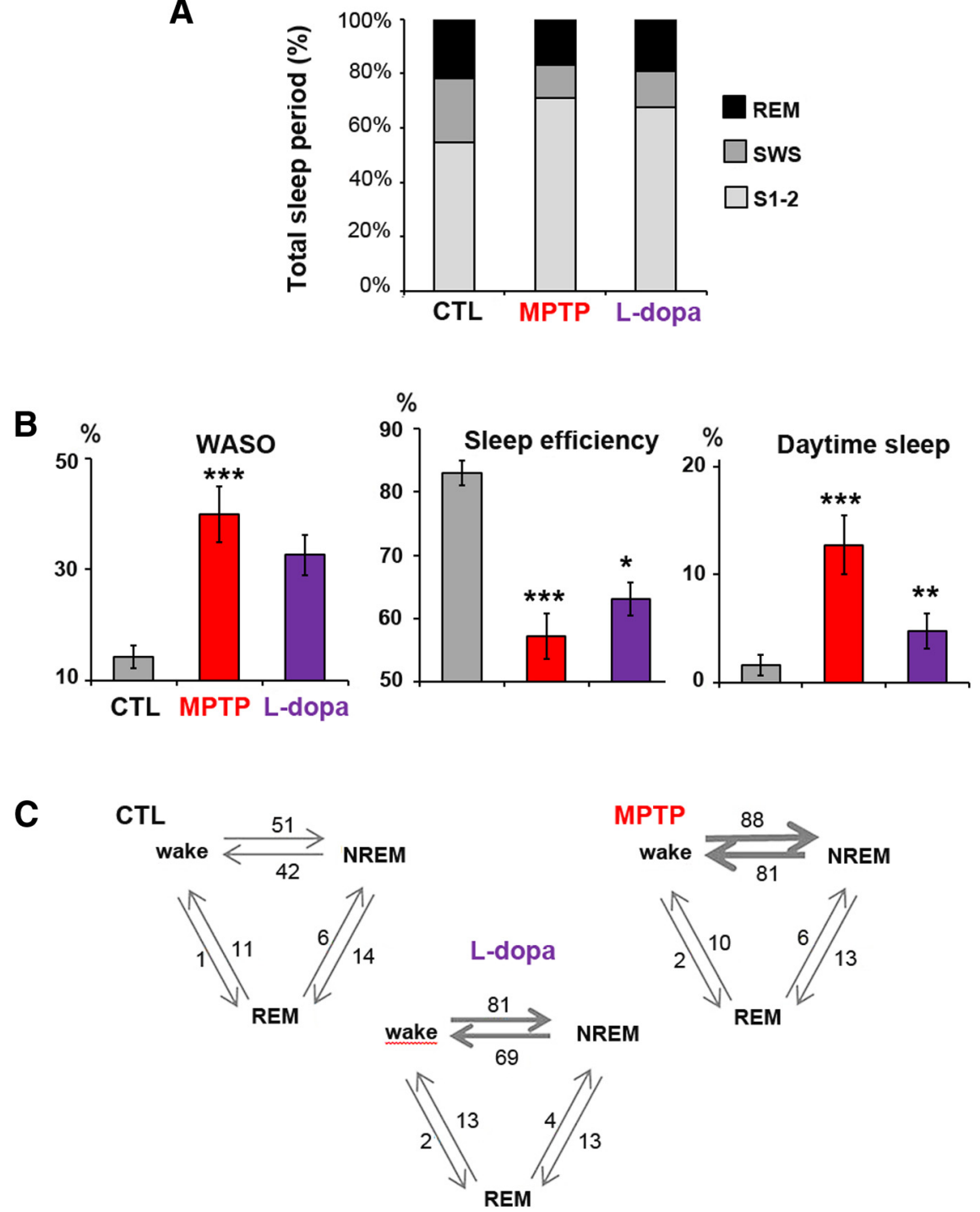

Figure 4. Sleep disorders after MPTP intoxication and partial improvement after L-dopa treatment. $\boldsymbol{A}$, Comparison of the contribution of REM, Stages 1 and 2 and SWS, expressed as a percentage of the total sleep period in the 4 macaques in the control state (CTL), after MPTP intoxication, and after L-dopa treatment. $\boldsymbol{B}$, Histograms showing increase in duration of WASO, reduction of sleep efficiency (ratio of total sleep time to the $12 \mathrm{~h}$ of nighttime), and development of daytime sleepiness (expressed as percentage of time spent asleep during the $12 \mathrm{~h}$ of daytime), and their improvement after L-dopa treatment. C, Transitions between wake, NREM, and REM periods. The mean number of transitions is given and is represented by the thickness of the arrows. The number of transitions between wake and NREM stages was increased after MPTP intoxication and improved slightly after L-dopa treatment.

lesion induced $\delta$ wave activity occurring during wake time in the three animals (Fig. 2C), as assessed on videotapes. These sleep disorders progressively improved from 1 to 3 weeks after PPN lesion (Fig. 3), similarly to the partial recovery from gait disorders. Three weeks after PPN lesion, all sleep parameters had returned to values before the PPN lesion, with a slight increase in sleep efficiency, and a decrease of awakenings during the night. However, the most severely disabled macaque was still unable to sleep in his usual sitting position, which most likely interfered with the sleep-wake cycle. Because of severe disequilibrium and falls, he was killed 3 weeks after PPN lesion. A second PPN lesion was performed contralaterally in one of the two other macaques. This second lesion induced a statistically significant and specific loss of $77 \%$ of $\mathrm{NADPH}^{+}$neurons compared with control animals, accompanied by a negligible $2 \%-3 \%$ loss of noncholinergic neurons in the PPN and in the cuneiform nucleus. A slight, transient decrease in REM sleep and SWS was observed a week after the lesion, without $\delta$ wave activity during wake time. Again, the animal slept slightly better 3 weeks after the second PPN lesion than after MPTP intoxication, with a slight increase in sleep efficiency, and a decrease of awakenings during the night (Fig. 6B).

\section{Discussion}

In this study, we showed that L-dopa treatment improved sleep disturbances induced by MPTP intoxication in macaques. Further cholinergic PPN lesion enhanced sleep quality. To our knowledge, this is the first longitudinal study in which sleep parameters were analyzed in the same monkey during the control state, after MPTP intoxication, under L-dopa treatment, and after PPN lesion. Because normal sleep architecture may vary across subjects, this experimental approach allows a precise description of the pathological state compared with the control state.

At baseline, nocturnal sleep parameters in the adult macaques of the present study were similar to those already described (Hsieh et al., 2008; Barraud et al., 2009). The first MPTP injection induced a dramatic decrease in SWS and REM sleep, as previously reported (Barraud et al., 2009). These symptoms increased after the stabilization of parkinsonian symptoms but without returning to the baseline score. On the whole, reduced sleep efficiency as well as a marked increase in insomnia and the number of nocturnal awakenings were observed. All these sleep disturbances were similar to those reported in MPTP-treated macaques (Almirall et al., 1999; Barraud et al., 2009; Hyacinthe et al., 2014) and in patients with advanced PD (Wailke et al., 2011; Yong et al., 2011), whereas sleep is not altered in de novo patients (Brunner et al., 2002; Kaynak et al., 2005). Our MPTPtreated macaques were markedly disabled and displayed a severe DA neuronal loss in the substantia nigra and a much smaller but significant DA degeneration in the ventral tegmental area as previously reported (Mounayar et al., 2007), and are therefore reminiscent of advanced PD. In addition, because a robust increase in the firing rate of DA neurons of the ventral tegmental area occurs during REM sleep (Dahan et al., 2007), the DA lesion in our MPTP-treated monkeys might account for the reduction of REM sleep, supporting the involvement of the DA system in the regulation of the sleep-wake cycle.

Although most of the sleep disorders in our parkinsonian macaques were similar to those described in parkinsonian patients, one element lacking was REM sleep behavior disorder (RBD). Indeed, the only movements observed during REM sleep were falls or awakenings; no abnormal behavior or violent movement 


\section{CTL}

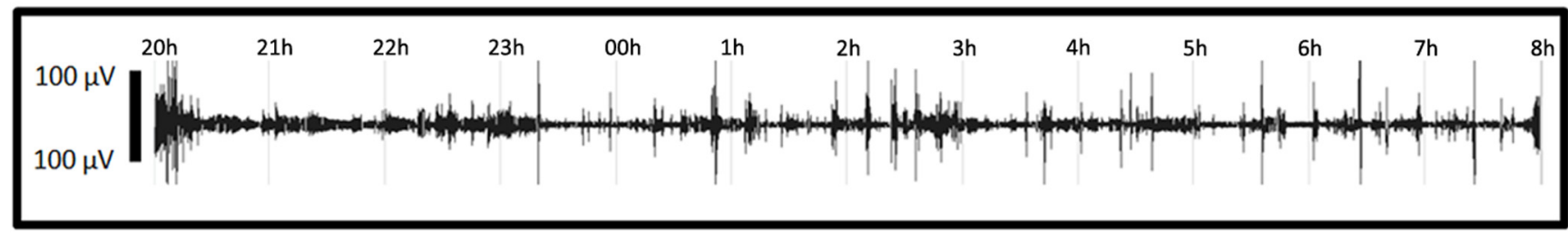

MPTP

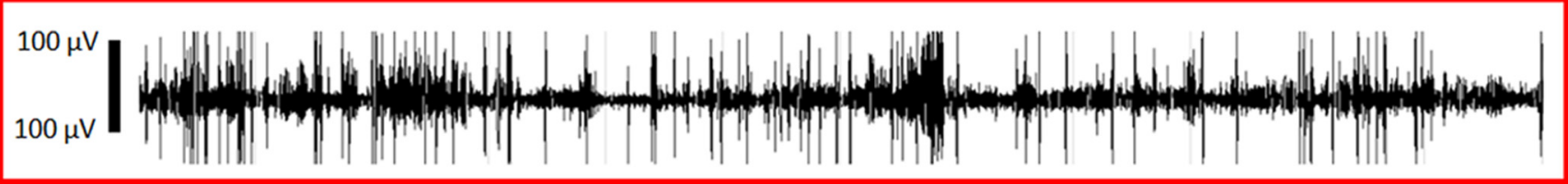

L-dopa

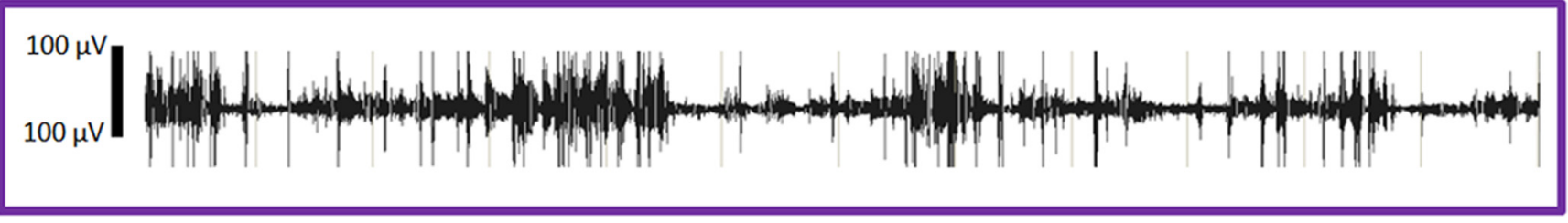

Figure 5. Examples of EMG recordings during the $12 \mathrm{~h}$ of nighttime sleep, at baseline (CTL) (first line), after MPTP intoxication (second line), and after L-dopa treatment in Macaque 2. The increase in muscle tone and in the number of movements that developed in the MPTP state was slightly improved after L-dopa treatment.

was observed, despite the fact that muscle tone was enhanced. The neuronal origin of RBD in PD might be a dysfunction of the subcoeruleus nucleus because it was reported to control atonia during REM sleep (Boeve et al., 2007), and to display a significant decrease in signal intensity on magnetic resonance images obtained in PD patients with RBD (García-Lorenzo et al., 2013). Therefore, the lack of RBD in our parkinsonian macaques might be the result of the absence of lesion within the locus coeruleus, as we and others observed (Herrero et al., 1993a). Moreover, the increased muscle tone during REM sleep in our MPTP-treated macaques may be equivalent to REM sleep without atonia in patients with PD (Gagnon et al., 2002; Arnulf, 2012). Similarly, Verhave et al. (2011) reported an enhancement of muscle tone during REM sleep in MPTP-treated marmosets, but no increase in phasic muscle tone (twitching) and no abnormal behavior. Together, these results suggest that DA deficiency increases tonic muscle activity during REM sleep (loss of atonia) but does not affect either the phasic or behavioral components during this sleep state.

Our results in MPTP-treated macaques show that L-dopa treatment not only decreased the number of movements and nocturnal awakenings but also had a beneficial effect on sleep architecture. L-Dopa was also found to be effective in patients with advanced PD for treating nighttime bradykinesia during awakenings but had no impact on the otherwise altered sleep structure and even induced a trend toward decreased total sleep period (Wailke et al., 2011). Several reasons may explain this discrepancy. First, all our animals were young and were treated with L-dopa twice a day for 8-12 d. In contrast, L-dopa is administered in middle-aged patients and for years. Thus, age effects and pharmacokinetics might be different in the patients and our monkeys. It is thus possible that L-dopa was still bioavailable at night at a dose sufficiently low to induce beneficial effects on sleep architecture in our animals, whereas the dosage has to be suitably adapted to the dopaminergic deficiency in each individual pa- tient. Second, sleep recordings under L-dopa treatment in our macaques were directly compared with those obtained after MPTP intoxication and before any L-dopa medication. These conditions are impossible to reproduce in PD patients because sleep recordings under L-dopa are compared with those obtained after withdrawal of levodopa for no more than $24 \mathrm{~h}$. It is also possible that the existence of non-DA lesions in PD limits the positive effect of L-dopa medication.

All our MPTP-treated macaques displayed an increase in daytime sleepiness, as also reported previously (Rye, 2010). Such symptoms cannot be solely a consequence of DA treatment because they were observed in the absence of L-dopa in MPTPtreated macaques and they often precede PD by several years in patients (Abbott et al., 2005). Daytime sleepiness would rather be an early marker of DA loss in humans and the first consequence of DA deficiency (Arnulf et al., 2002). The fact that daytime sleep was increased with motor disability and was decreased by L-dopa treatment further supports a direct role of dopamine in stimulating arousal systems. This is consistent with previous findings that high levels of levodopa were associated with increased alertness in parkinsonian patients (Arnulf et al., 2002; Bliwise et al., 2012). This raises the hypothesis that DA deficiency plays a role in the physiopathology of excessive daytime sleepiness. However, it should be kept in mind that patients with a higher levodopa equivalent dosage have a more advanced-stage disease.

A PPN lesion in our MPTP-treated macaques without L-dopa medication induced acute, transient, sleep disturbances, which were more severe in the most disabled macaque. These acute disturbances may be explained by postural deficits that resulted from PPN lesion and most likely interfered with the sleep-wake cycle. A temporary induction of $\delta$ wave activity during wake time resulted from PPN lesion in our MPTP-treated macaques, as already reported after destruction of the reticular formation in cats (Denoyer et al., 1991) or after administration of an anticholinergic compound (Longo, 1956). This reinforces the hypothesis 
A

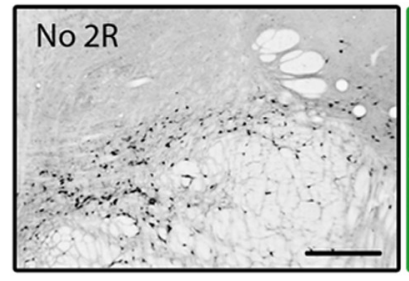

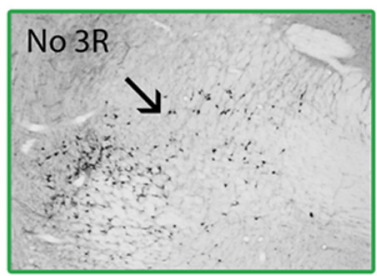

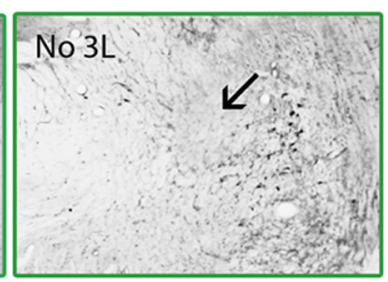

B

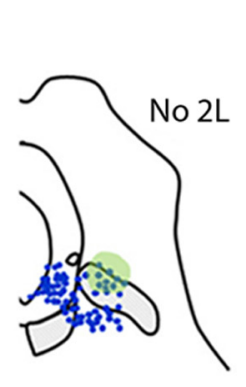

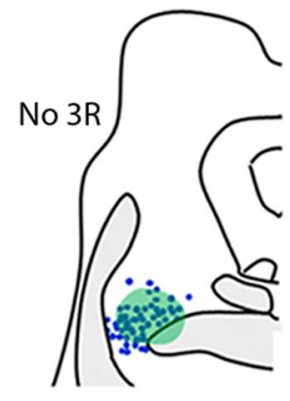

Number of NADPH neurons
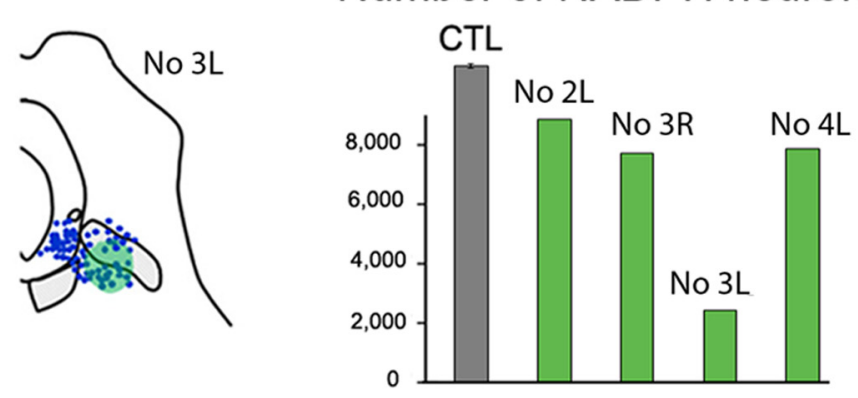

C
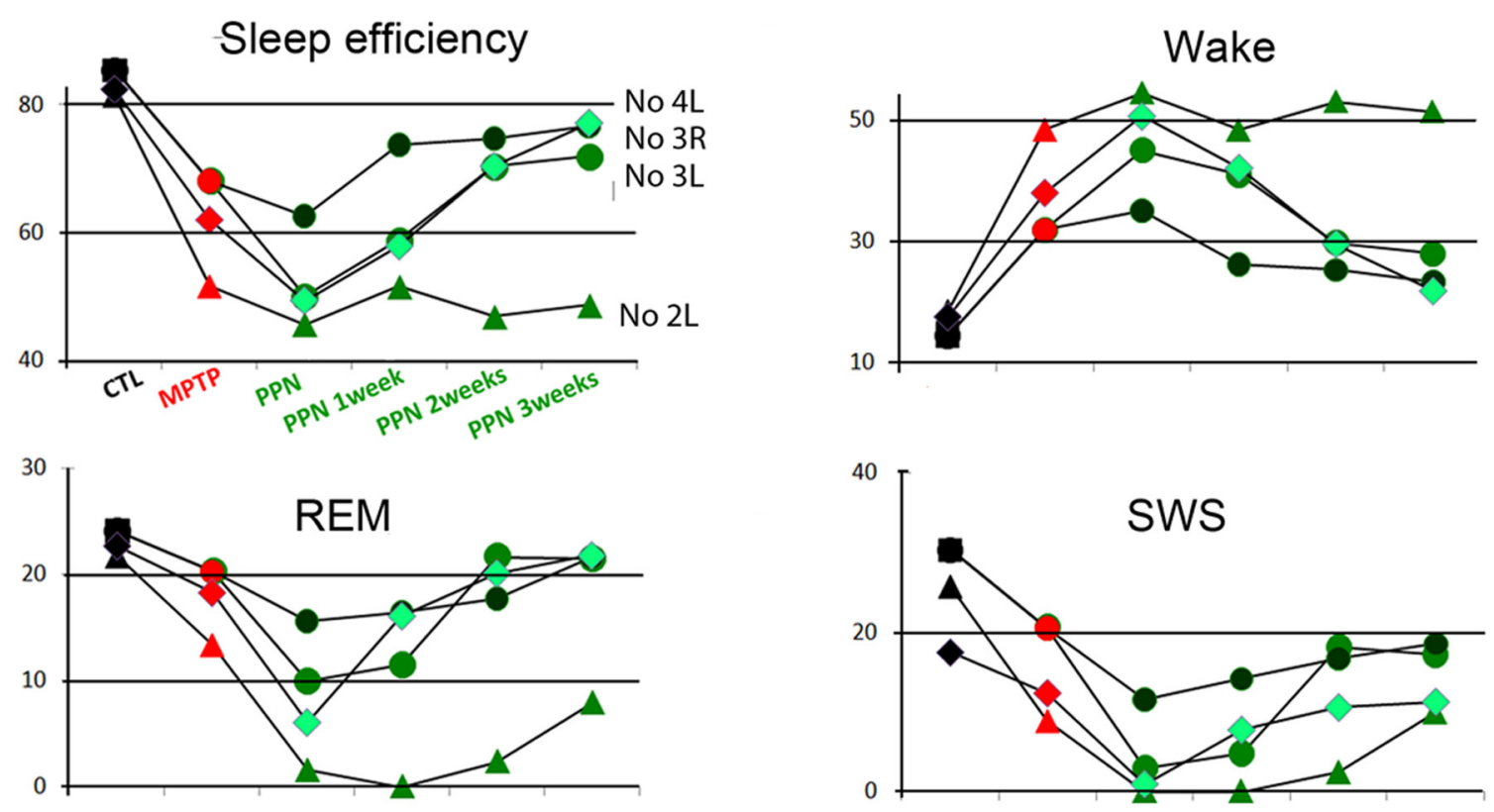

Figure 6. Effect of PPN lesion on sleep in three MPTP-treated macaques. $A$, Photomicrographs of PPN sections labeled for NADPH histochemistry, showing the toxin injection site into the PPN (arrow) in the left (L) side of Macaque 2 and in both sides of Macaque 3 compared with the right ( $\mathrm{R}$ ) unlesioned side of Macaque 2. B, Left, NADPH ${ }^{+}$neurons (blue) were mapped in two lesioned animals. Each dot represents an NADPH ${ }^{+}$neuron. Right, Quantification of the total number of $\mathrm{NADPH}^{+}$neurons in the PPN showing the neuronal loss for unilaterally lesioned macaques (Macaques 2 and 4), and for bilaterally lesioned macaque (Macaque 3). C, Values of relevant sleep parameters in the three macaques 1-3 weeks after PPN lesion compared with control (CTL) and MPTP values. Note a decrease of sleep efficiency, REM sleep and SWS, and an increase of nighttime awakenings (wake). These disorders were much more severe in Macaque 2 than in Macaques 3 and 4 . These parameters progressively returned to values observed after MPTP treatment, except for Macaque 2, which was therefore killed 3 weeks after PPN lesion. Scale bar: $A, 1 \mathrm{~mm}$.

that the cholinergic activation of the cortex, by the PPN projections to the thalamocortical pathway, results in a suppression of slow $\delta$ waves and induction of cortical arousal.

The fact that sleep disturbances progressively returned to values observed before the PPN lesion, at least in the less severely parkinsonian animals, suggests that compensatory processes had occurred. Transient effects of PPN lesions on REM sleep have also been reported in cats (Webster and Jones, 1988). Postlesion compensatory mechanisms are still poorly understood, but they may involve the remaining cholinergic neurons of the PPN or of the adjacent laterodorsal tegmental nucleus. Noradrenergic neurons of the locus coeruleus and the serotoninergic neurons of the raphe nucleus, which both participate in sleep regulation, also degenerate in parkinsonian patients. The remaining neurons may also take over to compensate for the loss of cholinergic PPN neurons. Thus, the lack of changes in sleep, and in particular in REM sleep, 3 weeks after PPN lesion in our MPTP-intoxicated macaques, as reported in normal cats 2 weeks after discrete PPN lesion (Shouse and Siegel, 1992), suggests that other systems involved in sleep control were spared.

One of the main findings of our study is that PPN lesion slightly improved sleep quality after 3 weeks. This is reminiscent of our previous observations that PPN lesion improved motor symptoms in MPTP-treated macaques (Grabli et al., 2013). It is possible that PPN lesion results in a reduction of its excitatory 
outputs to the subthalamic nucleus, which is overactive in PD. Indeed, a reversal of subthalamic nucleus hyperactivity has also been reported after PPN lesion in a 6-hydroxydopamine rat model (Breit et al., 2006). This would suggest that improvement of sleep quality after PPN lesion is a consequence of a reduction in nighttime bradykinesia. In this context, recent clinical data obtained in parkinsonian patients who were implanted with electrodes for deep-brain stimulation of the PPN to treat severe gait disorders indicate that sleep was strongly modified by PPN stimulation. Whereas high-frequency PPN stimulation induced NREM sleep, low-frequency stimulation increased alertness during the daytime and produced a long-term improvement of nighttime sleep (Arnulf et al., 2010; Peppe et al., 2012). It is difficult to compare these data with those obtained in MPTP-treated macaques after PPN lesion. However, our data suggest that the effects obtained in patients are the result of stimulation of both cholinergic and noncholinergic neuronal populations. Additional experiments are needed to determine the neuronal circuits that mediate parkinsonian sleep disorders.

In conclusion, combining DA and PPN lesions in macaques allowed us to characterize sleep disorders in a model of advanced PD. Using this approach, we demonstrated an improvement of sleep quality after L-dopa therapy and the involvement of the $\mathrm{PPN}$ in the regulation of the sleep/wake cycle.

\section{References}

Abbott RD, Ross GW, White LR, Tanner CM, Masaki KH, Nelson JS, Curb JD, Petrovitch H (2005) Excessive daytime sleepiness and subsequent development of Parkinson disease. Neurology 65:1442-1446. CrossRef Medline

Almirall H, Pigarev I, de la Calzada MD, Pigareva M, Herrero MT, Sagales T (1999) Nocturnal sleep structure and temperature slope in MPTP treated monkeys. J Neural Transm 106:1125-1134. CrossRef Medline

Arnulf I (2005) Excessive daytime sleepiness in parkinsonism. Sleep Med Rev 9:185-200. CrossRef Medline

Arnulf I (2012) REM sleep behavior disorder: motor manifestations and pathophysiology. Mov Disord 27:677-689. CrossRef Medline

Arnulf I, Konofal E, Merino-Andreu M, Houeto JL, Mesnage V, Welter ML, Lacomblez L, Golmard JL, Derenne JP, Agid Y (2002) Parkinson's disease and sleepiness: an integral part of PD. Neurology 58:1019-1024. CrossRef Medline

Arnulf I, Ferraye M, Fraix V, Benabid AL, Chabardès S, Goetz L, Pollak P, Debû B (2010) Sleep induced by stimulation in the human pedunculopontine nucleus area. Ann Neurol 67:546-549. CrossRef Medline

Barbato L, Stocchi F, Monge A, Vacca L, Ruggieri S, Nordera G, Marsden CD (1997) The long-duration action of levodopa may be due to a postsynaptic effect. Clin Neuropharmacol 20:394-401. CrossRef Medline

Barraud Q, Lambrecq V, Forni C, McGuire S, Hill M, Bioulac B, Balzamo E, Bezard E, Tison F, Ghorayeb I (2009) Sleep disorders in Parkinson's disease: the contribution of the MPTP non-human primate model. Exp Neurol 219:574-582. CrossRef Medline

Bezard E, Imbert C, Deloire X, Bioulac B, Gross CE (1997) A chronic MPTP model reproducing the slow evolution of Parkinson's disease: evolution of motor symptoms in the monkey. Brain Res 766:107-112. CrossRef Medline

Bliwise DL, Trotti LM, Wilson AG, Greer SA, Wood-Siverio C, Juncos JJ, Factor SA, Freeman A, Rye DB (2012) Daytime alertness in Parkinson's disease: potentially dose-dependent, divergent effects by drug class. Mov Disord 27:1118-1124. CrossRef Medline

Boeve BF, Silber MH, Saper CB, Ferman TJ, Dickson DW, Parisi JE, Benarroch EE, Ahlskog JE, Smith GE, Caselli RC, Tippman-Peikert M, Olson EJ, Lin SC, Young T, Wszolek Z, Schenck CH, Mahowald MW, Castillo PR, Del Tredici K, Braak H (2007) Pathophysiology of REM sleep behaviour disorder and relevance to neurodegenerative disease. Brain 130: 2770-2788. CrossRef Medline

Breit S, Lessmann L, Unterbrink D, Popa RC, Gasser T, Schulz JB (2006) Lesion of the pedunculopontine nucleus reverses hyperactivity of the subthalamic nucleus and substantia nigra pars reticulata in a 6-hydroxydopamine rat model. Eur J Neurosci 24:2275-2282. CrossRef Medline

Brunner H, Wetter TC, Hogl B, Yassouridis A, Trenkwalder C, Friess E (2002) Microstructure of the non-rapid eye movement sleep electroencephalogram in patients with newly diagnosed Parkinson's disease: effects of dopaminergic treatment. Mov Disord 17:928-933. CrossRef Medline

Clark SD, Nothacker HP, Wang Z, Saito Y, Leslie FM, Civelli O (2001) The urotensin II receptor is expressed in the cholinergic mesopontine tegmentum of the rat. Brain Res 923:120-127. CrossRef Medline

Clark SD, Alderson HL, Winn P, Latimer MP, Nothacker HP, Civelli O (2007) Fusion of diphtheria toxin and urotensin II produces a neurotoxin selective for cholinergic neurons in the rat mesopontine tegmentum. J Neurochem 102:112-120. CrossRef Medline

Dahan L, Astier B, Vautrelle N, Urbain N, Kocsis B, Chouvet G (2007) Prominent burst of firing neurons in the ventral tegmental area during paradoxical sleep. Neuropsychopharmacology 32:1232-1241. CrossRef Medline

Denoyer M, Sallanon M, Buda C, Kitahama K, Jouvet M (1991) Neurotoxic lesion of the mesencephalic reticular formation and/or the posterior hypothalamus does not alter waking in the cat. Brain Res 539:287-303. CrossRef Medline

François C, Yelnik J, Tandé D, Agid Y, Hirsch EC (1999) Dopaminergic cell group A8 in the monkey: anatomical organization and projections to the striatum. J Comp Neurol 414:334-347. CrossRef Medline

Gagnon JF, Bédard MA, Fantini ML, Petit D, Panisset M, Rompré S, Carrier J, Montplaisir J (2002) REM sleep behavior disorder and REM sleep without atonia in Parkinson's disease. Neurology 59:585-589. CrossRef Medline

García-Lorenzo D, Longo-Dos Santos C, Ewenczyk C, Leu-Semenescu S, Gallea C, Quattrocchi G, Pita Lobo P, Poupon C, Benali H, Arnulf I, Vidailhet M, Lehericy S (2013) The coeruleus/subcoeruleus complex in rapid eye movement sleep behaviour disorders in Parkinson's disease. Brain 136:2120-2129. CrossRef Medline

Grabli D, Karachi C, Folgoas E, Monfort M, Tande D, Clark S, Civelli O, Hirsch EC, François C (2013) Gait disorders in parkinsonian monkeys with pedunculopontine nucleus lesions: a tale of two systems. J Neurosci 33:11986-11993. CrossRef Medline

Herrero MT, Hirsch EC, Javoy-Agid F, Obeso JA, Agid Y (1993a) Differential vulnerability to 1 -methyl-4-phenyl-1,2,3,6-tetrahydropyridine of dopaminergic and cholinergic neurons in the monkey mesopontine tegmentum. Brain Res 624:281-285. CrossRef Medline

Herrero MT, Perez-Otaño I, Oset C, Kastner A, Hirsch EC, Agid Y, Luquin MR, Obeso JA, Del Rio J (1993b) GM-1 ganglioside promotes the recovery of surviving midbrain dopaminergic neurons in MPTP-treated monkeys. Neuroscience 56:965-972. CrossRef Medline

Hirsch EC, Graybiel AM, Duyckaerts C, Javoy-Agid F (1987) Neuronal loss in the pedunculopontine tegmental nucleus in Parkinson disease and in progressive supranuclear palsy. Proc Natl Acad Sci U S A 84:5976-5980. CrossRef Medline

Hobson DE, Lang AE, Martin WW, Razmy A, Rivest J, Fleming J (2002) Excessive daytime sleepiness and sudden-onset sleep in Parkinson disease: a survey by the Canadian Movement Disorder Group. JAMA 287: 455-463. CrossRef Medline

Hsieh KC, Robinson EL, Fuller CA (2008) Sleep architecture in unrestrained rhesus monkeys (Macaca mulatta) synchronized to 24-hour light-dark cycles. Sleep 31:1239-1250. Medline

Hyacinthe C, Barraud Q, Tison F, Bezard E, Ghorayeb I (2014) D1 receptor agonist improves sleep-wake parameters in experimental parkinsonism. Neurobiol Dis 63:20-24. CrossRef Medline

Jellinger K (1988) The pedunculopontine nucleus in Parkinson's disease, progressive supranuclear palsy and Alzheimer's disease. J Neurol Neurosurg Psychiatry 51:540 -543. CrossRef Medline

Karachi C, Grabli D, Bernard FA, Tandé D, Wattiez N, Belaid H, Bardinet E, Prigent A, Nothacker HP, Hunot S, Hartmann A, Lehéricy S, Hirsch EC, François C (2010) Cholinergic mesencephalic neurons are involved in gait and postural disorders in Parkinson disease. J Clin Invest 120:27452754. CrossRef Medline

Kaynak D, Kiziltan G, Kaynak H, Benbir G, Uysal O (2005) Sleep and sleepiness in patients with Parkinson's disease before and after dopaminergic treatment. Eur J Neurol 12:199-207. CrossRef Medline 
Longo VG (1956) Effects of scopolamine and atropine electroencephalographic and behavioral reactions due to hypothalamic stimulation. J Pharmacol Exp Ther 116:198-208. Medline

Mounayar S, Boulet S, Tandé D, Jan C, Pessiglione M, Hirsch EC, Féger J, Savasta M, François C, Tremblay L (2007) A new model to study compensatory mechanisms in MPTP-treated monkeys exhibiting recovery. Brain 130:2898-2914. CrossRef Medline

Peppe A, Pierantozzi M, Baiamonte V, Moschella V, Caltagirone C, Stanzione P, Stefani A (2012) Deep brain stimulation of pedunculopontine tegmental nucleus: role in sleep modulation in advanced Parkinson disease patients: one-year follow-up. Sleep 35:1637-1642. CrossRef Medline

Rye DB (2006) Excessive daytime sleepiness and unintended sleep in Parkinson's disease. Curr Neurol Neurosci Rep 6:169-176. CrossRef Medline

Rye D (2010) Seeing beyond one's nose: sleep disruption and excessive sleepiness accompany motor disability in the MPTP treated primate. Exp Neurol 222:179-180. CrossRef Medline

Shouse MN, Siegel JM (1992) Pontine regulation of REM sleep components in cats: integrity of the pedunculopontine tegmentum (PPT) is important for phasic events but unnecessary for atonia during REM sleep. Brain Res 571:50-63. CrossRef Medline

Verhave PS, Jongsma MJ, Van den Berg RM, Vis JC, Vanwersch RA, Smit AB, Van Someren EJ, Philippens IH (2011) REM sleep behavior disorder in the marmoset MPTP model of early Parkinson disease. Sleep 34:1119 1125. CrossRef Medline

Wailke S, Herzog J, Witt K, Deuschl G, Volkmann J (2011) Effect of controlled-release levodopa on the microstructure of sleep in Parkinson's disease. Eur J Neurol 18:590-596. CrossRef Medline

Webster HH, Jones BE (1988) Neurotoxic lesions of the dorsolateral pontomesencephalic tegmentum-cholinergic cell area in the cat: II. Effects upon sleep-waking states. Brain Res 458:285-302. CrossRef Medline

Yong MH, Fook-Chong S, Pavanni R, Lim LL, Tan EK (2011) Case control polysomnographic studies of sleep disorders in Parkinson's disease. PLoS One 6:e22511. CrossRef Medline 